\title{
Neonatal Fc receptor for IgG regulates mucosal immune responses to luminal bacteria
}

\author{
Masaru Yoshida, ${ }^{1}$ Kanna Kobayashi, ${ }^{1}$ Timothy T. Kuo, ${ }^{1}$ Lynn Bry, ${ }^{2}$ \\ Jonathan N. Glickman, ${ }^{2}$ Steven M. Claypool, ${ }^{1}$ Arthur Kaser, ${ }^{1}$ Takashi Nagaishi, ${ }^{1}$ \\ Darren E. Higgins, ${ }^{3}$ Emiko Mizoguchi, ${ }^{4}$ Yoshio Wakatsuki, ${ }^{5}$ Derry C. Roopenian, ${ }^{6}$ \\ Atsushi Mizoguchi, ${ }^{4}$ Wayne I. Lencer, ${ }^{7,8}$ and Richard S. Blumberg ${ }^{1,8}$
}

\begin{abstract}
${ }^{1}$ Gastroenterology Division, Department of Medicine, Brigham and Women's Hospital, 2Department of Pathology, Brigham and Women's Hospital, and ${ }^{3}$ Department of Microbiology and Molecular Genetics, Harvard Medical School, Boston, Massachusetts, USA. "Department of Pathology, Massachusetts General Hospital, Boston, Massachusetts, USA. ${ }^{5}$ Division of Clinical Bioregulatory Science, Kyoto University, Kyoto, Japan. ${ }^{6}$ The Jackson Laboratory, Bar Harbor, Maine, USA. 7 Gastrointestinal Cell Biology, Department of Medicine, Children's Hospital, Boston, Massachusetts, USA. ${ }^{8}$ Harvard Digestive Disease Center, Boston, Massachusetts, USA.
\end{abstract}

\begin{abstract}
The neonatal Fc receptor for IgG (FcRn) plays a major role in regulating host IgG levels and transporting IgG and associated antigens across polarized epithelial barriers. Selective expression of FcRn in the epithelium is shown here to be associated with secretion of IgG into the lumen that allows for defense against an epithelium-associated pathogen (Citrobacter rodentium). This pathway of host resistance to a bacterial pathogen as mediated by FcRn involves retrieval of bacterial antigens from the lumen and initiation of adaptive immune responses in regional lymphoid structures. Epithelial-associated FcRn, through its ability to secrete and absorb IgG, may thus integrate luminal antigen encounters with systemic immune compartments and as such provide essential host defense and immunoregulatory functions at the mucosal surfaces.
\end{abstract}

\section{Introduction}

Secretory Igs such as IgA, IgM, and IgG that are present in mucosal surfaces potentially provide a first line of defense against microorganisms (1-3). Secretory IgA (sIgA) is well known to be transported across epithelial cells into the lumen through an active unidirectional process by the polymeric Ig receptor ( $\mathrm{pIgR}$ ) (4). In addition to sIgA, significant quantities of IgG can also be secreted into the intestinal lumen of adult humans and rodents. It has been reported that nasal secretions contain $300 \mu \mathrm{g} / \mathrm{ml} \mathrm{IgG} \mathrm{(4),} \mathrm{and} \mathrm{approximate-}$ ly $800 \mu \mathrm{g} / \mathrm{ml} \mathrm{IgG} \mathrm{can} \mathrm{be} \mathrm{detected} \mathrm{in} \mathrm{the} \mathrm{human} \mathrm{rectum} \mathrm{(5).} \mathrm{Like}$ sIgA, which has been well documented as actively participating in the defense against some pathogens $(3,6)$, mucosally associated IgG has also been recently suggested to contribute to host defense $(1,2)$. However, despite all that is known about IgA transport and its relation to mucosal host defense, the role of intestinal luminal $\mathrm{IgG}$ in defending against enteric bacteria and the mechanisms by which this is achieved remains to be established.

It has been previously shown that $\operatorname{IgG}$ can be transported across intact epithelial barriers through the placenta in humans and neonatal intestine in rodents for the passive transfer of immunity from mother to fetus or into the neonatal host, respectively. The receptor responsible for mediating this transport is the neonatal $\mathrm{Fc}$ receptor for $\operatorname{IgG}(\mathrm{FcRn})$, a $\beta 2$-microglobulin-associated ( $\beta 2 \mathrm{~m}$-associated), major histocompatibility complex class I-related molecule that is also responsible for the protection of $\operatorname{IgG}$ from catabolism through-

Nonstandard abbreviations used: FcRn, neonatal Fc receptor for IgG; GALT, gut-associated lymphoid tissue; IFABP, intestinal fatty acid-binding protein gene promoter; $\beta 2 \mathrm{~m}, \beta 2$-microglobulin; $\mathrm{m}$-, mouse; MLN, mesenteric lymph node.

Conflict of interest: R.S. Blumberg and W.I. Lencer have an equity interest in Syntonix Pharmaceuticals Inc., which is developing FcRn-related therapeutics.

Citation for this article: J. Clin. Invest. 116:2142-2151 (2006). doi:10.1172/JCI27821. out life in the circulation through its expression on endothelia and potentially other cell types (7). It has been recently appreciated that significant levels of $\mathrm{FcRn}$ are also constitutively expressed by epithelial cells throughout life in human intestine, lung, and kidney $(8,9)$. This is in contrast to expression of $\mathrm{FcRn}$ in the intestinal epithelia of rodents, which is developmentally regulated - in that FcRn is highly expressed at birth with a dramatic decrease of expression occurring after 2 weeks of life at the time of weaning. The recent identification of FcRn expression in numerous epithelial cell types in humans during adult life and more recently in other mammals such as nonhuman primates (10), together with the recognition that FcRn mediates the bidirectional transport of $\operatorname{IgG}$ (from basolateral to apical as well as from apical to basolateral surfaces) in vitro and in vivo across epithelial barriers, has directed attention to other potential extensions of $\mathrm{FcRn}$ function in immunity beyond the passive transfer of IgG and the protection of IgG from catabolism $(2,8,11-13)$. Specifically, this bidirectional transport of IgG confers a unique ability on FcRn to retrieve intestinal luminal antigens as a complex with $\operatorname{IgG}$ and deposit them into the intestinal mucosa, where the antigen/IgG complexes can be captured by DCs for subsequent presentation to $\mathrm{CD}^{+} \mathrm{T}$ cells (2). These properties of $\mathrm{FcRn}$ define a unique mechanism by which absorptive epithelia, which covers the majority of the surface of the intestines, can specifically acquire and transport antigens into the lamina propria. Consistent with this, recent studies have indicated that intestinal bacterial antigens are required to direct the maturation of immune responses (14) and that such immune responses are induced throughout the intestine rather than within restricted regions such as Peyer's patches (15). Therefore, these recent observations have raised a potential possibility that epithelial cell-mediated sampling of luminal bacterial antigens throughout the intestinal surface contributes to the regulation of mucosal and systemic immune responses. 
A

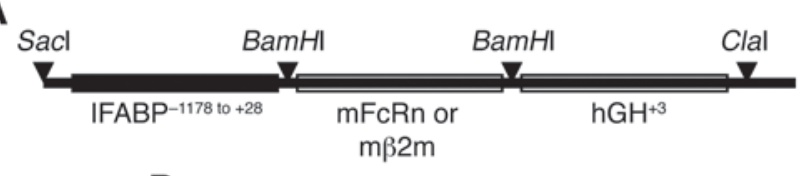

B

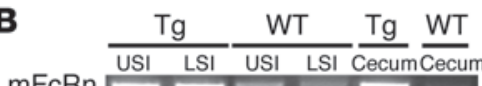
$\mathrm{mFCRn}=$ $\mathrm{m} \beta$-actin

C

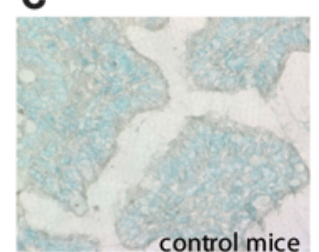

I

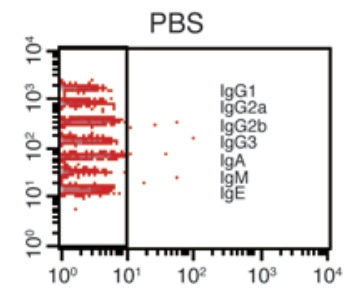

D

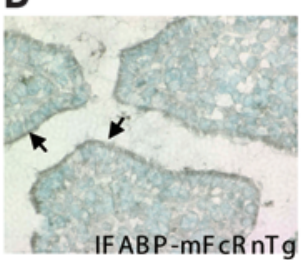

E

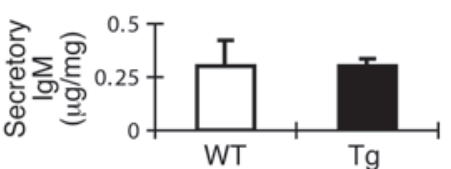

$\mathbf{F}$

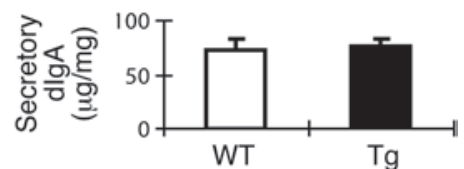

G

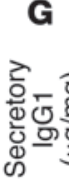

G

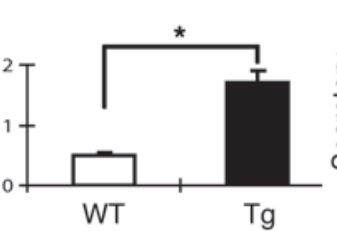

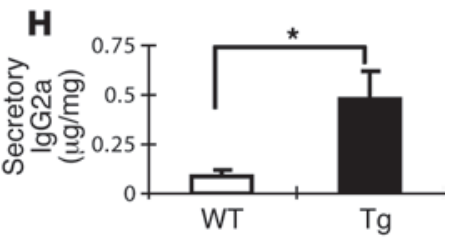

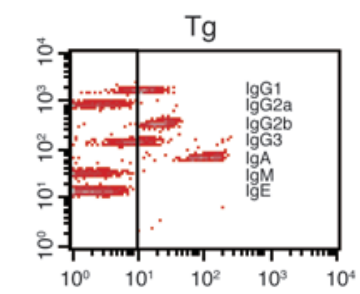

Kappa
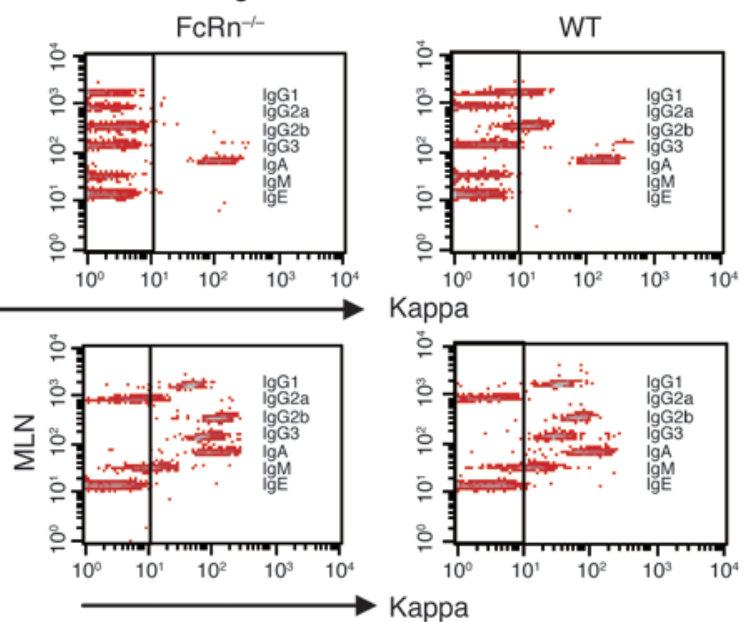

Figure 1

Absence of intestinal luminal IgG in FcRn ${ }^{-/-}$mice. (A) The construct for the Tg IFABP-mFcRnTg/m $\beta 2 m T g$ mouse, designed to express mFcRn and $m \beta 2 m$ under the control of the IFABP. (B) Increased $m F c R n$ expression in epithelial cells of IFABP-mFcRnTg/m $32 \mathrm{mTg}$ (Tg) mouse. RNA was extracted from epithelial cells of upper and lower small intestines (USI and LSI, respectively) and cecum in 6-week-old IFABP-mFcRnTg/ $\mathrm{m} \beta 2 \mathrm{mTg}$ founder BALB/c mice and littermate WT BALB/c mice and subjected to RT-PCR. (C and D) Immunohistochemical analysis of lower small intestine in WT (C) and IFABP-mFcRnTg/m $32 \mathrm{mTg}$ mice (D). Arrows indicate staining of FcRn. (E-H) The levels of Igs secreted into the intestinal lumen. Secretory IgM (E), dimeric IgA (F), IgG1 (G), and IgG2a (H) were measured by ELISA. The mean \pm SD are shown for each group $(n=8)$. ${ }^{*} P<0.05$. (I) The levels of Igs (IgG1, IgG2a, IgG2b, IgG3, IgA, IgM, and IgE) secreted into the lumen of the indicated mouse strains on a C57BL/ 6 background were measured by a cytometric bead array.

We therefore investigated the role of FcRn within the intestinal epithelia in host defense by examining the response to Citrobacter rodentium. This bacterium is normally restricted in its localization to the epithelium, and its eradication is highly dependent upon $\mathrm{CD}^{+} \mathrm{T}$ cell responses and IgG (16-18). The separation of the antigens associated with this bacterium within the epithelium from the other mucosal and systemic tissues implies that eradication of this organism must require an immunologic pathway that integrates and regulates the function of these compartments. We therefore reasoned that $\mathrm{FcRn}$ provides this integrating function by virtue of its transport properties and, in so doing, would confirm a unique role for FcRn in host defense. To confirm this hypothesis, we generated a mouse model in which FcRn is expressed constitutively and solely by intestinal epithelial cells in adult life. Using this mouse model we dissected the biological roles of intestinal epithelial cell-associated FcRn during infection with an epithelial cell-associated pathogen and showed that FcRn participated in the eradication of this pathogen through a pathway that involves its transport functions and ability to direct antigens to inductive sites associated with mucosal tissues.

\section{Results}

Establishment of intestine-specific mouse FcRn Tg mice. To study the role of mouse FcRn $(\mathrm{mFcRn})$ in intestinal epithelium in mediating antimicrobial immunity, since the expression of FcRn has been shown to decrease at the time of weaning in rodents (19), we established FcRn Tg mouse lines in which $\mathrm{mFcRn}$ and $\mathrm{m} \beta 2 \mathrm{~m}$ were specifically expressed by intestinal epithelial cells (Figure 1A) using the intestinal fatty acid-binding protein gene promoter (IFABP; ref. 20) to create IFABP-mFcRnTg/m $\beta 2 \mathrm{mTg}$ mice (20). We expressed $\beta 2 \mathrm{~m}$ in this manner to ensure that it was not substrate limiting in expression of the FcRn transgene. Two founder lines that expressed FcRn in the epithelium at the highest levels were selected in this study. RT-PCR analysis showed that the Tg 

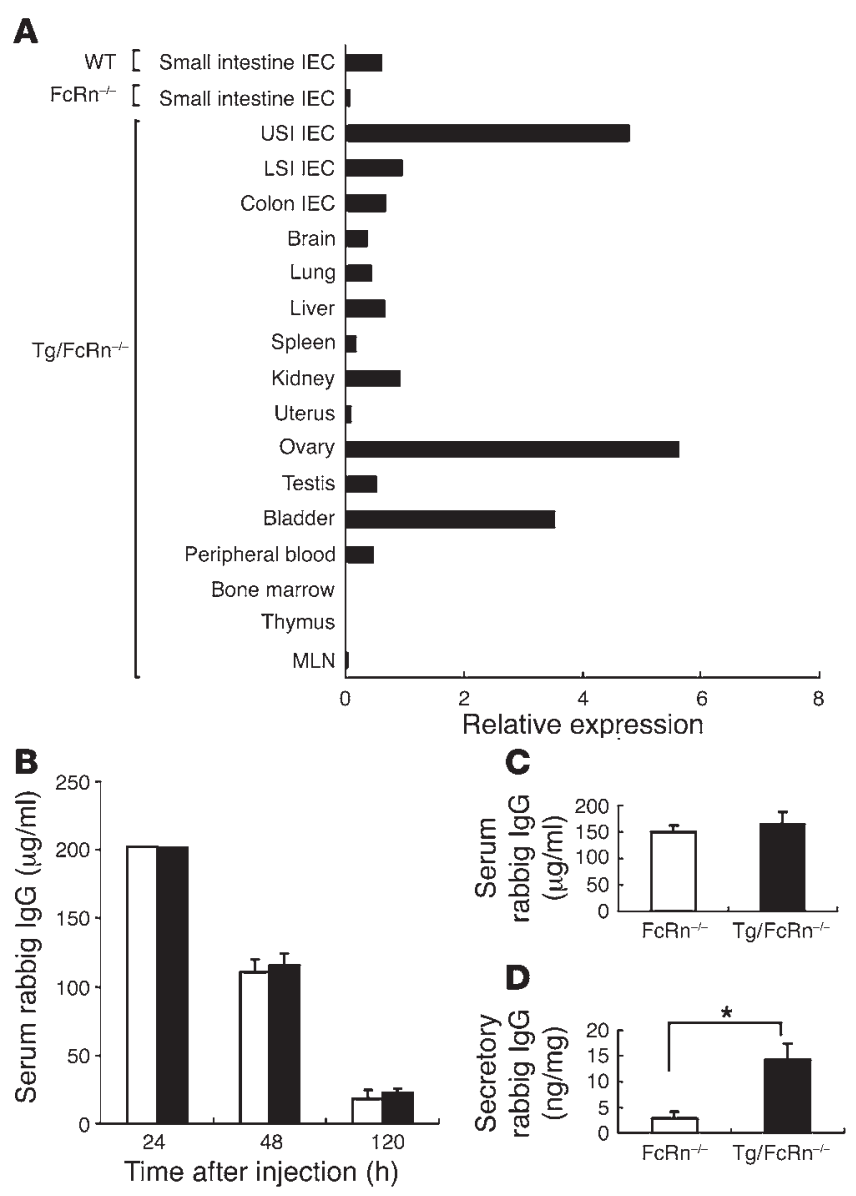

C

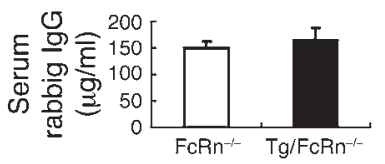

D

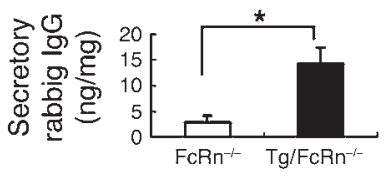

lines most strongly expressed FcRn in epithelial cells of the upper and lower intestine and cecum at 6 weeks of age compared with control BALB/c mice, which weakly expressed $\mathrm{mFcRn}$ (Figure 1B). In contrast, the levels of $\mathrm{m} \beta 2 \mathrm{~m}$ expression were indistinguishable between $\mathrm{Tg}$ and WT mice. These findings are consistent with a decrease in $\mathrm{FcRn}$, but not $\beta 2 \mathrm{~m}$, expression in mice after weaning. To further confirm the RT-PCR results at the protein level, immunohistochemical analysis was also performed. An increase in FcRn was detected in the epithelial cells of lower small intestine (Figure 1D) and cecum (data not shown) of IFABP-mFcRnTg/ $\mathrm{m} \beta 2 \mathrm{mTg}$ mice compared with WT littermate controls, consistent with the activity of this promoter (Figure 1C) (20). These data indicate that IFABP-mFcRnTg/m $\beta 2 \mathrm{mTg}$ mice express increased FcRn protein as well as mRNA in the epithelium of the small intestine and cecum in adult mice relative to WT littermate controls.

FcRn-mediated transport of IgG across the epithelial barrier. Since FcRn has been demonstrated to be involved in the secretion of IgG from tissue spaces into the lumen through epithelial cells in a mouse expressing a human transgene under the control of its endogenous promoter (2), we next examined the secretory levels of Igs including IgA, IgM, and IgG within the intestinal lumen of IFABP-mFcRnTg/ $\mathrm{m} \beta 2 \mathrm{mTg}$ and WT littermate control BALB/c mice by ELISA. IFABP$\mathrm{mFcRnTg} / \mathrm{m} \beta 2 \mathrm{mTg}$ mice exhibited significant secretion of IgG1 and IgG2a, but not IgA or IgM, into the intestinal lumen (Figure 1, E-H). This finding was further confirmed by an alternative approach using a cytometric bead array with IFABP-mFcRnTg/m $32 \mathrm{mTg}$ mice on a different genetic background (C57BL/6) compared with WT lit-

\section{Figure 2}

IgG transport into the lumen of IFABP-mFcRnTg/m $\beta 2 \mathrm{mTg} / \mathrm{FcRn}^{-/}$ mice. (A) Quantitative PCR of CDNA using PCR primers originating in exon 2 in variety of tissues in IFABP-mFcRnTg/m $32 \mathrm{mTg} / \mathrm{FcRn}^{-/-}$ $\left(\mathrm{Tg} / \mathrm{FcRn}^{-/-}\right)$mice. IEC, intestinal epithelial cells. (B) Serum rabbit IgG levels in IFABP-mFcRnTg/m $\beta 2 \mathrm{mTg} / \mathrm{FcRn}^{-1-}$ (black bars) and littermate control FcRn ${ }^{-1-}$ mice (white bars) at 24, 48, and 120 hours after injection of rabbit IgG. (C) Serum rabbit IgG levels in IFABP$\mathrm{mFcRnTg} / \mathrm{m} \beta 2 \mathrm{mTg} / \mathrm{FcRn}^{-1-}$ mice measured at 12 hours after injection of rabbit lgG $(n=4)$. (D) Secretory rabbit lgG levels in feces of IFABP$\mathrm{mFcRnTg} / \mathrm{m} \beta 2 \mathrm{mTg} / \mathrm{FcRn}^{-1-}$ mice measured at 12 hours after injection of rabbit IgG as ng per mg of feces $(n=4)$. ${ }^{*} P<0.05$.

termate controls and $\mathrm{FcRn}^{-/}$mice on the same genetic background (Figure 1I). No IgG was detected in the feces of $\mathrm{FcRn}^{-1-} \mathrm{C} 57 \mathrm{BL} / 6$ mice, whereas low levels of IgGs were detectable in the feces of WT control C57BL/6 mice, which express low levels of FcRn in the epithelium (Figure 1B). This latter observation is notable because our studies indicate that FcRn expression (Figure 1B) and function (Figure 1I) are not completely extinguished in adult life, but are just markedly diminished relative to neonatal rodents. This is consistent with previous predictions by Ward and colleagues (19) that FcRn is decreased 1,000-fold in adult mice after weaning relative to neonatal mice, which express extremely high levels of $\mathrm{FcRn}$ for passive acquisition of IgG from maternal milk. More significantly, increased quantities of secretory IgG1, IgG2b, and IgG3 were detected in the feces of IFABP-mFcRnTg/m $\beta 2 \mathrm{mTg}$ C57BL $/ 6$ mice, in which intestinal epithelial FcRn expression is enhanced compared with WT and especially $\mathrm{FcRn}^{-/}$mice (Figure 1I, top panels). In contrast, after the culture of mesenteric lymph node (MLN) cells from these mouse groups without any in vitro stimulation for 2 hours at $37^{\circ} \mathrm{C}$, similar levels of IgGs were detected in the culture medium. This indicates that the absence of intestinal IgG secretion in $\mathrm{FcRn}^{-/}$mice was not due to decreased IgG production (Figure 1I, bottom panels). The absence of detectable IgG2a was due to the genetic background of the mice examined, C57BL/6, as these mice do not express this isotype of IgG.

Given the low-level expression of FcRn observed in intestinal epithelia of WT mice by RT-PCR (Figure 1B), IFABP-mFcRnTg/ $\mathrm{m} \beta 2 \mathrm{mTg}$ mice were further backcrossed onto a $\mathrm{FcRn}^{-/-}$background to generate IFABP-mFcRnTg $/ \mathrm{m} \beta 2 \mathrm{mTg} / \mathrm{FcRn}^{-/-}$mice in order to limit FcRn expression and function to the epithelium. This would allow for comparison with mice in which FcRn expression was extinguished in the intestinal epithelium, as observed in $\mathrm{FcRn}^{-/-}$mice. Figure 2A shows an analysis of FcRn expression as defined by quantitative PCR analysis of a variety of tissues from IFABP-mFcRnTg $/ \mathrm{m} \beta 2 \mathrm{mTg} / \mathrm{FcRn}^{-/}$mice compared with WT and $\mathrm{FcRn}^{-1-}$ mice. As previously reported (20-22), FcRn expression in the IFABP-mFcRnTg $/ \mathrm{m} \beta 2 \mathrm{mTg} / \mathrm{FcRn}{ }^{-/-}$mice was mainly observed in the intestinal epithelium of the small intestine. In addition, significant expression of FcRn was also observed in the ovaries and bladders of IFABP-mFcRnTg $/ \mathrm{m} \beta 2 \mathrm{mTg} / \mathrm{FcRn}^{-/-}$mice. Low-level FcRn expression was detected in the colon, brains, lungs, livers, kidneys, testes, and peripheral blood but not the spleens, uteri, bone marrow, thymi, or MLNs of IFABP- $\mathrm{mFcRnTg} / \mathrm{m} \beta 2 \mathrm{mTg} /$ $\mathrm{FcRn}^{-} /$- mice. Importantly, there was no detectable $\mathrm{FcRn}$ expression in intestinal epithelia of $\mathrm{FcRn}^{-1}$ mice, as predicted (23), but lowlevel FcRn was detected in WT mice, consistent with the RT-PCR results shown in Figure 1B. These studies show that Tg expression of FcRn under the control of the IFABP reconstitutes FcRn expression levels in the intestinal epithelium in $\mathrm{FcRn}^{-/}$-mice. 
A
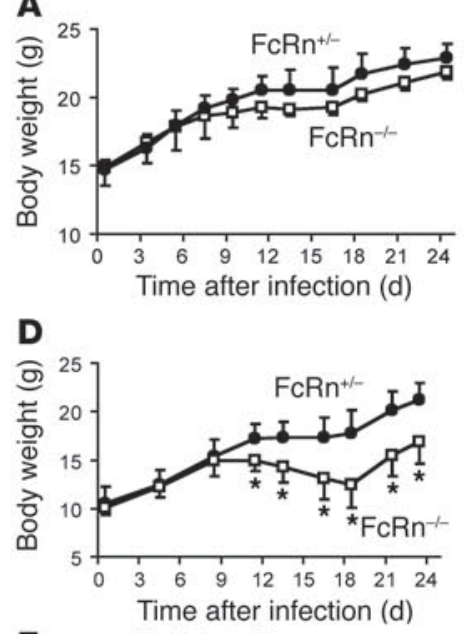

B

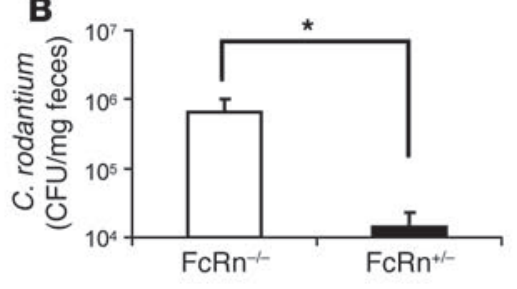

E
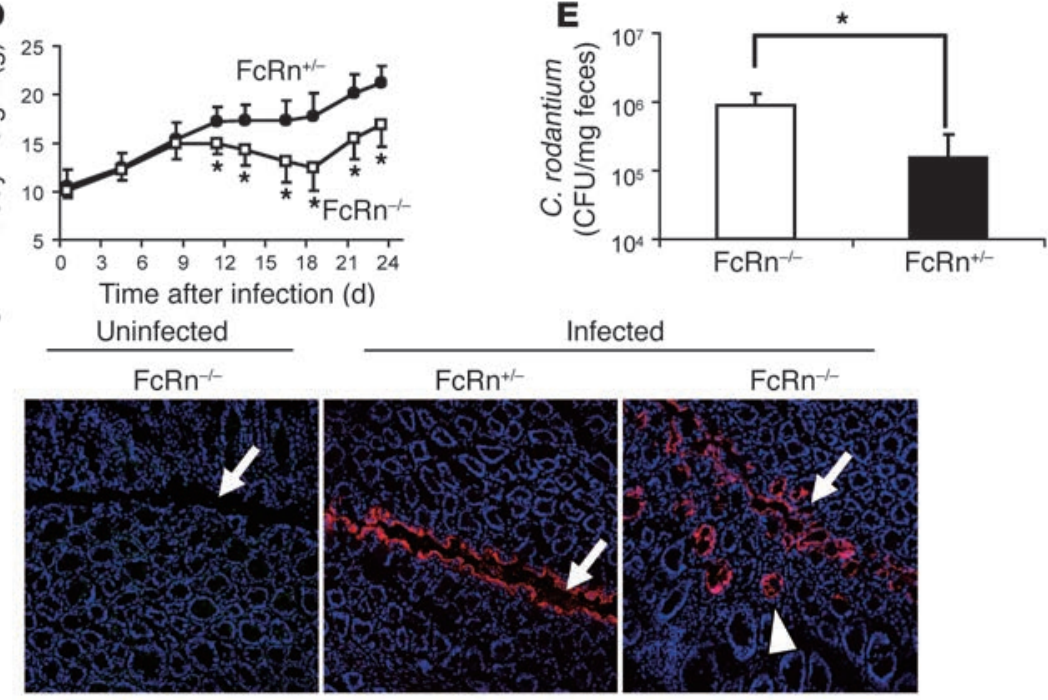

Infected
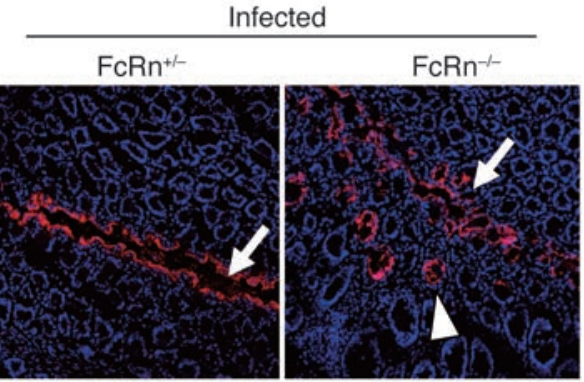

Uninfected

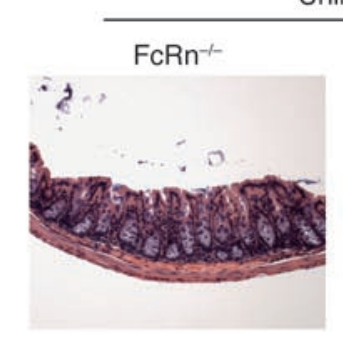

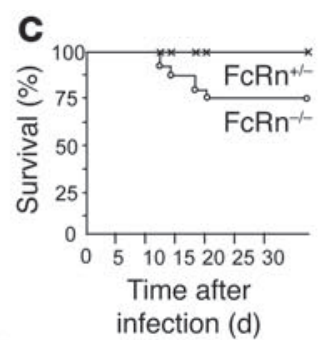

G

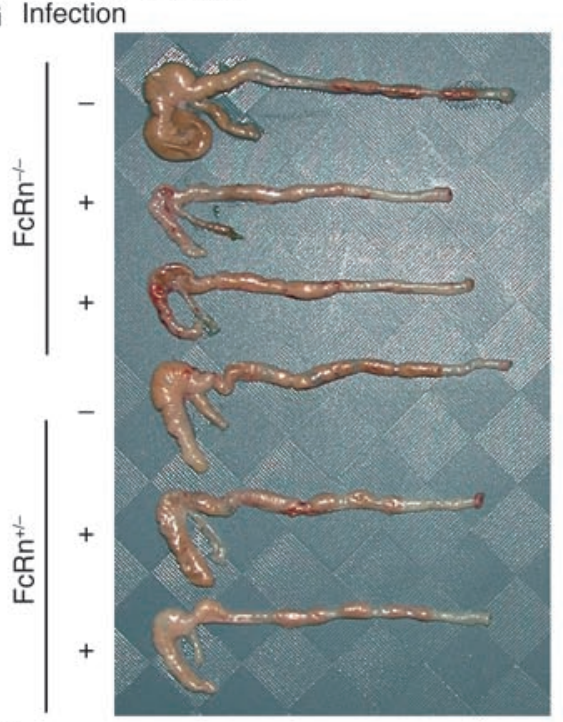

H
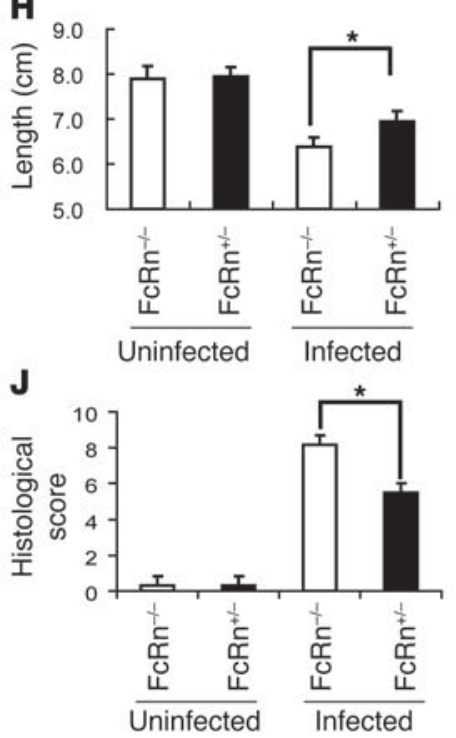

\section{Figure 3}

Susceptibility to $C$. rodentium infection in the presence of $\mathrm{FcRn}$. (A and B) Susceptibility to infection with $1 \times 10^{9} \mathrm{CFU}$ of $C$. rodentium in $\mathrm{FcRn}-1-$ BALB/c mice. (A) Body weight changes in $\mathrm{FcRn}^{-1-}$ and $\mathrm{FcRn}^{+/-}$mice with $\mathrm{C}$. rodentium infection. (B) CFU of $C$. rodentium in feces of $\mathrm{FcRn}{ }^{-/-}$and $\mathrm{FcRn}^{+/-}$mice 21 days after infection. Mean $\pm \mathrm{SD}$ are shown for each group $(n=6)$. (C-E) Susceptibility to infection with $C$. rodentium in $\mathrm{FcRn}^{-/-}$ C57BL/6 mice. Survival rate (C) and body weight changes (D) in $\mathrm{FcRn}^{-1-}$ and $\mathrm{FcRn}^{+/-}$mice with C. rodentium infection. (E) CFU of $C$. rodentium in feces of $\mathrm{FcRn}^{-/-}$and $\mathrm{FcRn}^{-/+}$mice 21 days after infection. Mean $\pm \mathrm{SD}$ are shown for each group $(n=8)$. (F) Immunohistochemical analysis of the colon to detect intimin in mice with C. rodentium infection. Colonic tissues were collected at day 7 from selected mice on a C57BL/6 background. Sections were stained for intimin using a polyclonal rabbit anti-C. rodentium intimin antibody (red) and nuclei (blue) and were examined by confocal microscopy. Magnification, $\times 400$. Macroscopic findings $(\mathbf{G})$ and the length of colon $(\mathbf{H})$ in $\mathrm{FcRn}^{-1-}$ and FcRn ${ }^{+/-} \mathrm{C} 57 \mathrm{BL} / 6 \mathrm{mice}$, uninfected or infected with C. rodentium, at 21 days after infection. (I) Histological findings of colon in $\mathrm{FcRn}^{-1-}$ and littermate $\mathrm{FcRn}{ }^{+/-} \mathrm{C} 57 \mathrm{BL} / 6$ mice with or without $C$. rodentium infection (21 days after infection). Magnification, $\times 100$. (J) Histological score of colonic tissue in the mice with or without C. rodentium infection at day $21 .{ }^{*} P<0.05$. 
A

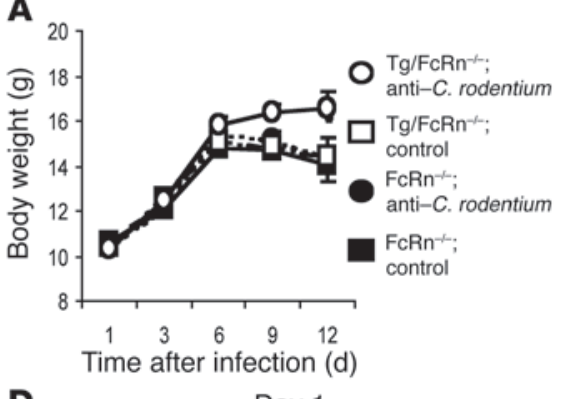

B

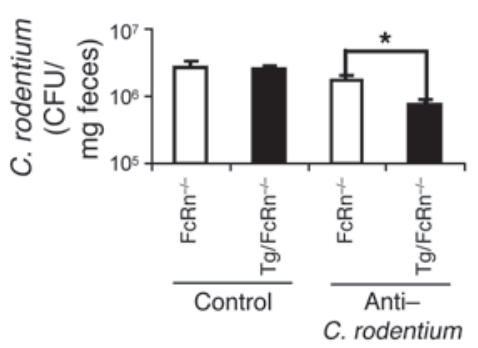

C

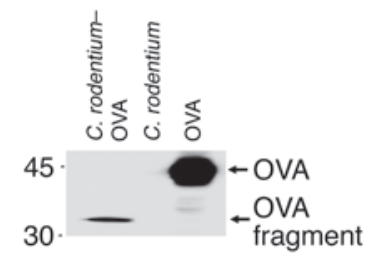

D

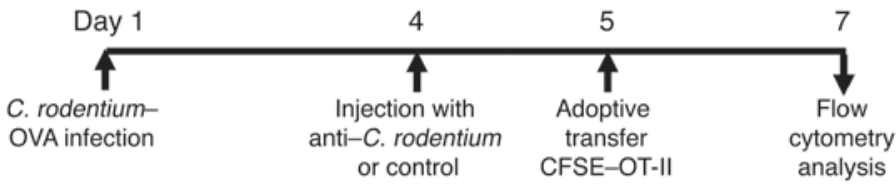

E

$\mathrm{FcRn}^{-1-}$
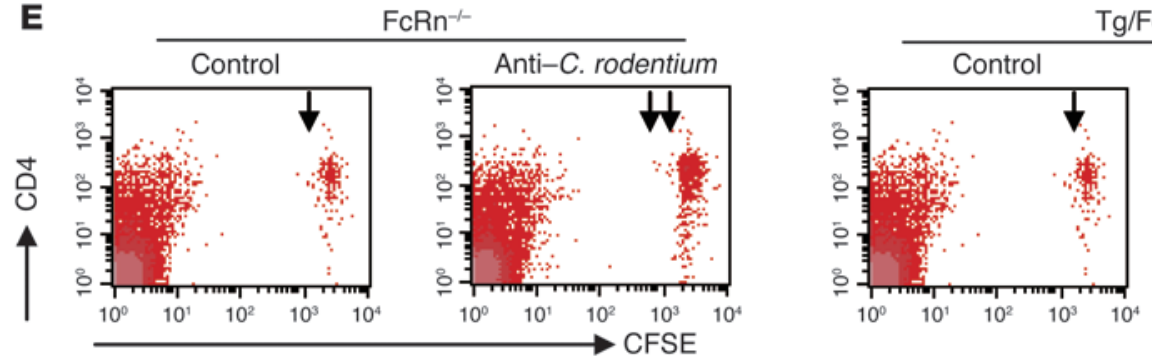

$\mathrm{Tg} / \mathrm{FcRn}^{--}$

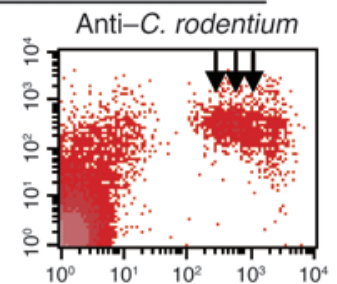

$\mathbf{F}$

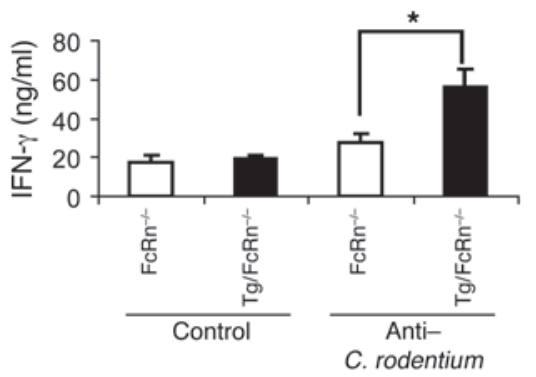

G

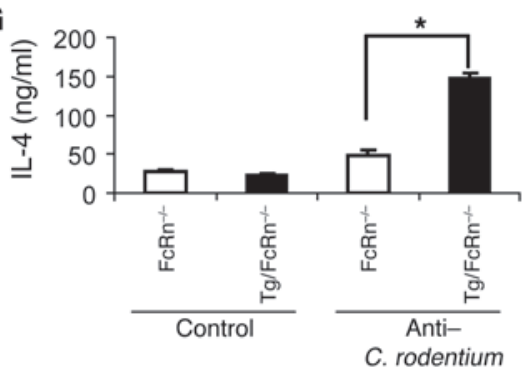

Figure 4

Induction of immune response to $C$. rodentium-derived antigen in the presence of circulating IgG and FcRn in intestinal epithelial cells. (A and $\mathbf{B})$ The effect of FcRn-mediated IgG transport into the intestinal lumen in C. rodentium infection. Body weight changes (A) and CFU of $C$. rodentium in feces 21 days after infection (B) in IFABP-mFcRnTg/m $32 \mathrm{mTg} / \mathrm{FcRn}^{-1-}$ and FcRn ${ }^{-/-} \mathrm{C} 57 \mathrm{BL} / 6$ mice with i.v. injection of anti-C. rodentium IgG or control lgG. Mean \pm SD are shown for each group $(n=6)$. (C) Establishment of a genetically engineered $C$. rodentium strain that constitutively produces an OVA fragment. The immunoblot confirms the expression of the OVA fragment by $C$. rodentium. (D) Summary of the experimental protocol, with the inoculation of $C$. rodentium-OVA or control bacteria, the injection of anti-C. rodentium IgG or control IgG, and the adoptive transfer of CD45.1+CD4+OVA-specific T cells from CD45.1+OT-II mice. (E) The number of OVA-specific CD4+ T cells in the MLNs in IFABP-mFcRnTg/ $\mathrm{m} \beta 2 \mathrm{mTg} / \mathrm{FcRn}^{-1-}$ and $\mathrm{FcRn}^{-1-}$ mice increased in the presence of anti-C. rodentium IgG or control IgG ( $n=3$ ). Arrows indicate increasing rounds of cell division. (F and $\mathbf{G}$ ) Cytokine production in OVA-specific CD4+ T cells purified from the MLNs and cultured with OVA for 48 hours in vitro. Cytokine production of IFN- $\gamma(\mathbf{F})$ and IL-4 $(\mathbf{G})$ was measured by ELISA. Mean \pm SD are shown for each group $(n=4)$. ${ }^{\star} P<0.05$.

We next directly examined whether FcRn in intestinal epithelial cells transports IgG into mucosal secretions, as we previously showed using human FcRn Tg mice (2). To determine whether i.v. injected $\operatorname{IgG}$ could be transported into the lumen across the epithelial barrier by FcRn-dependent transcytosis, IFABP-mFcRnTg/ $\mathrm{m} \beta 2 \mathrm{mTg} / \mathrm{FcRn}^{-/-}$mice were examined for their ability to transmit rabbit IgG into the lumen. Since $\mathrm{mFcRn}$ can bind rabbit IgG as well as mouse IgG (24), rabbit IgG was injected i.v. into IFABP-mFcRnTg/ $\mathrm{m} \beta 2 \mathrm{mTg} / \mathrm{FcRn}^{-/-}$or littermate control $\mathrm{FcRn}^{-/-}$mice, and the levels of $\mathrm{IgG}$ in the serum and feces were examined. In the first group of studies, rabbit IgG was examined in the serum after i.v. injection over a period of 120 hours to determine whether IgG was catabo- lized differently in the presence of FcRn expression within the intestinal epithelium of $\mathrm{FcRn}^{-/-}$mice by virtue of $\mathrm{FcRn}$ expression driven by the IFABP. These studies showed that the rabbit IgG concentrations were identical in the IFABP-mFcRnTg $/ \mathrm{m} \beta 2 \mathrm{mTg} / \mathrm{FcRn}^{-/-}$and $\mathrm{FcRn}^{-/-}$mice over this time period, suggesting that the expression of FcRn under control of the IFABP contributes little to protecting IgG from catabolism (Figure $2 \mathrm{~B}$ ). Therefore, rabbit IgG was injected i.v. into IFABP-mFcRnTg/m $\beta 2 \mathrm{mTg} / \mathrm{FcRn}^{-/-}$and $\mathrm{FcRn}^{-/-}$ mice, and $\operatorname{IgG}$ levels were examined at 12 hours after injection. Although there were no differences in the levels of rabbit IgG in the sera at this time point (Figure 2C), rabbit IgG was detected at significantly higher levels in the feces of IFABP-mFcRnTg/m $\beta 2 \mathrm{mTg} /$ 

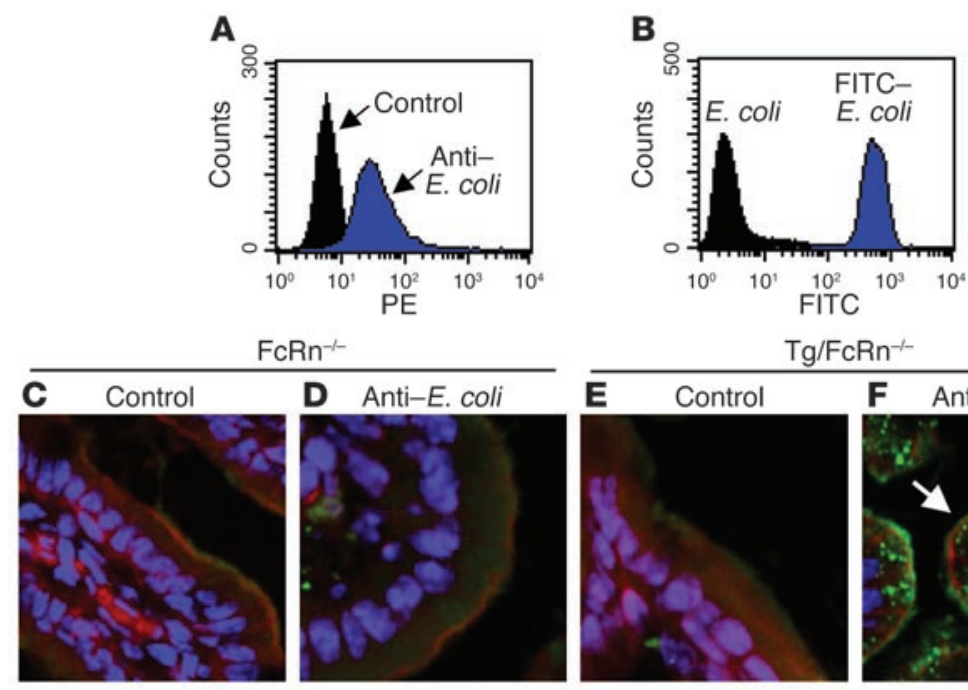

$\mathrm{FCRn}^{-1-}$
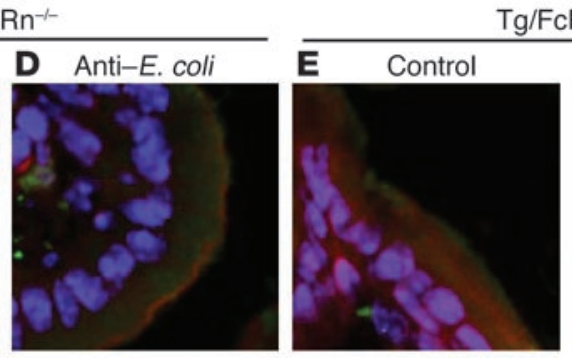

G

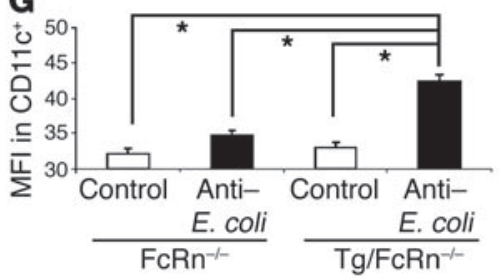

\section{Figure 5}

Luminal bacterial antigens transported as an immune complex across intestinal epithelial cells via FcRn in vivo. (A and B) Flow cytometry of rabbit anti-E. coli IgG and control IgG followed by PE-conjugated goat anti-rabbit IgG (A) and FITC-conjugated E. coli (B). (C-F) Confocal microscopy analysis of transport of bacterial antigens across intestinal epithelial cells. Sections were stained for actin (phalloidin; red) and nuclei (blue). Magnification, $\times 400$. Arrow in $\mathbf{F}$ illustrates transported FITC-conjugated $E$. coli in intestinal epithelial cells in the presence of rabbit anti-E. coli IgG. (G) Presence of FITC-conjugated $E$. coli in CD11 $\mathrm{c}^{+}$cells of the MLNs of IFABP-mFcRnTg/m $\beta 2 m T g / F c n^{-/}$ mice 5 hours after FITC-conjugated $E$. coli administration in the presence of rabbit anti-E. coli IgG. Mean fluorescence intensity (MFI) on gated $\mathrm{CD} 11 \mathrm{c}^{+}$cells is shown. The mean $\pm \mathrm{SD}$ was shown for each group $(n=4)$. ${ }^{*} P<0.05$.
$\mathrm{FcRn}^{-/-}$mice compared with littermate $\mathrm{FcRn}^{-/-}$mice (Figure 2D). These results indicate that FcRn expression solely in intestinal epithelial cells is involved in the transport of IgG into mucosal secretions and is the major means by which IgG enters the lumen.

FcRn-deficient mice are susceptible to infection with an epithelial cellspecific pathogen, C. rodentium. C. rodentium is a bacterial pathogen that causes a murine infectious colitis equivalent to enterohemorrhagic and enteropathogenic Escherichia coli infection in humans. This pathogen causes a primary infection that is associated with the apical surface of the gut epithelium. Importantly, CD4 ${ }^{+} \mathrm{T}$ cells, B cells, and IgG, but not secretory IgA or IgM, have been shown to play a critical role in prevention against this infection (16-18). Therefore, to test the pathophysiological role of FcRn-mediated IgG secretion into intestinal lumen in the C. rodentium infection, $\mathrm{FcRn}^{-/}$and littermate control $\left(\mathrm{FcRn}^{+/-}\right)$mice were orally inoculated with $1 \times 10^{9}$ of $C$. rodentium at 3 weeks of age. To exclude the possibility that the pathological changes in C. rodentium infection was directly related to the absence of FcRn and not to other alterations imposed by the knockout mouse model, both BALB/c and C57BL/ 6 background strains were used in this study. Previous studies have shown that both strains of mice exhibit differing sensitivities to C. rodentium infection, with greater clinical evidence of disease and a fecal burden of bacteria in C57BL/ 6 mice compared with BALB/c mice (25). Interestingly, $\mathrm{FCRn}^{-/-}$mice exhibited more body weight loss (Figure 3, A and D) and higher bacterial concentrations in the feces at 21 days after infection (Figure 3, $\mathrm{B}$ and $\mathrm{E})$ than did $\mathrm{FcRn}^{+/-}$mice, regardless of the genetic backgrounds, with more severe disease and increased levels of fecal bacteria in C57BL/ 6 mice as previously noted (25). Consistent with this finding, $\mathrm{FcRn}^{-/} \mathrm{C} 57 \mathrm{BL} / 6$ mice receiving C. rodentium orally demonstrated a decreased median survival rate, with only $75 \%$ of mice surviving at 30 days (Figure $3 \mathrm{C}$ ), although the surviving mice successfully cleared C. rodentium from their feces by 6 weeks after inoculation (data not shown). Increased amounts of C. rodentium were also detected within epithelial and subepithelial tissues of colon in $\mathrm{FcRn}^{-/}$mice at 7 days after infection (Figure 3F, right panel), without evidence of C. rodentium in the MLNs and spleen (data not shown). In contrast, C. rodentium infection was limited to the surface of the colonic intestinal epithelium in $\mathrm{FcRn}^{+/}$mice (Figure 3F, middle panel). No intimin staining was observed in the uninfected colon (Figure 3F, left panel). At the same time, there were no detectable differences in $C$. rodentium quantities in the feces at day $7\left(\mathrm{FcRn}^{-/-}, 3.4 \times 10^{8} \pm 9.2 \times 10^{7} \mathrm{CFU} / \mathrm{mg}\right.$ feces; $\mathrm{FcRn}^{+/}$, $3.2 \times 10^{8} \pm 5.9 \times 10^{7} \mathrm{CFU} / \mathrm{mg}$ feces; $\left.n=5 ; P=0.67\right)$. This suggests that one of the earliest events to occur in the FcRn-deficient state is penetration of $C$. rodentium into the epithelial and subepithelial tissues. Notably in this regard, $\mathrm{FcRn}^{+/-}$mice, but not $\mathrm{FcRn}^{-/-}$mice, contained significant levels of endogenous IgGs in the serum that could react serologically with $C$. rodentium before infection and at day 7 (Supplemental Figure 1; available online with this article; doi:10.1172/JCI27821DS1). These endogenous IgGs in naive animals, which presumably heterologously bind to C. rodentium but are directed at other bacteria, may be important to managing C. rodentium within epithelial and subepithelial tissues in the presence of FcRn expression within the epithelium.

At later time points (Supplemental Figure 1), a significant increase in presumably specific anti-C. rodentium IgGs was detected in the serum of $\mathrm{FcRn}^{+/}$mice at levels higher than those observed in $\mathrm{FcRn}^{-/-}$mice. This diminished serologic response in $\mathrm{FcRn}^{-/-}$mice, in association with an inability to secrete IgGs into the epithelium and lumen in the absence of FcRn expression in the epithelium, presumably limited the ability of FcRn-deficient mice to properly manage C. rodentium infection. Indeed, macroscopic and microscopic injury was greater in $\mathrm{FcRn}^{-/}$than in $\mathrm{FcRn}^{+/}$mice 
at day 21 after infection. The colons of $\mathrm{FcRn}^{-/}$mice were characterized by severe shortening and thickening compared with those of $\mathrm{FcRn}^{+/-}$mice (Figure 3, G and H). Consistent with these macroscopic changes, $\mathrm{FcRn}{ }^{-/-} \mathrm{C} 57 \mathrm{BL} / 6$ mice that were infected with C. rodentium exhibited increased mononuclear cell and neutrophil infiltration into the tissues and significantly increased epithelial injury compared with that observed in $\mathrm{FcRn}^{+/}$mice (Figure 3I). A quantitative evaluation of histological findings also confirmed the increased injury in the FcRn-/- mice (Figure 3J). These results indicate that $\mathrm{FcRn}^{-/}$mice, which show an absence of $\mathrm{FcRn}$ expression in the intestinal epithelium and intestinal luminal IgG (Figure 1I), are more susceptible to $C$. rodentium-induced colitis.

Anti-C. rodentium IgG improves infection via $m F c R n$ when expressed on intestinal epithelial cells. The above studies show that defense against an epithelial-associated pathogen is dependent upon FcRn expression. Since FcRn-deficient mice lack both FcRn expression in epithelia and high levels of serum IgG due to a lack of FcRn protection function, it was possible that the inability of these mice to resist C. rodentium infection was due to either or both of these deficiencies. Therefore, to test for the role of IgG and/or FcRn expression in epithelia, IFABP- $\mathrm{mFcRnTg} / \mathrm{m} \beta 2 \mathrm{mTg} / \mathrm{FcRn}^{-/-}$mice were compared with $\mathrm{FcRn}^{-/-}$mice for their ability to eradicate C. rodentium in the presence and absence of anti-C. rodentium IgG. To test whether specific IgG for bacteria is required for the regulation of $C$. rodentium infection through $\mathrm{FcRn}$-mediated transport of IgG, C. rodentium was orally inoculated into 3-week-old IFABP$\mathrm{mFcRnTg} / \mathrm{m} \beta 2 \mathrm{mTg} / \mathrm{FcRn}^{-/-}$and $\mathrm{FcRn}^{-/-}$mice that had received i.v. administration of either a polyclonal anti-C. rodentium antibody or a nonimmune control antibody. Whereas the control antibody had no effect on C. rodentium eradication in $\mathrm{FcRn}^{-/}$or $\mathrm{Tg}$ mice, the preadministration of specific antibody resulted in less body weight loss (Figure 4A) and lower bacterial concentrations in the feces (Figure 4B) in IFABP-mFcRnTg/m $\beta 2 \mathrm{mTg} / \mathrm{FcRn}^{-1}$ mice compared with $\mathrm{FcRn}^{-/}$mice. Decreased quantities of C. rodentium were also detected within the epithelial and subepithelial tissues of mice in the presence of both FcRn expression in epithelia and anti-C. rodentium IgG, as defined by immunohistochemistry (data not shown). These results indicate that $\mathrm{FcRn}$ expression in intestinal epithelial cells contributes to protecting against C. rodentium infection, but only in the presence of specific IgG antibodies.

Antibacterial IgG affects antigen-specific $C D 4^{+} T$ cell responses to $C$. rodentium when $F c R n$ is expressed in intestinal epithelial cells. Both innate and acquired immune responses are involved in the pathogenesis of infectious colitis (16-18). We have recently demonstrated that FcRn can retrieve luminal IgG/oral antigen (OVA) complexes into the intestinal mucosa, which activate antigen-specific immune responses systemically by transport of immune complexes to regional lymphatic tissues via DCs. To examine whether FcRn also plays a role in infection-induced acquired immune responses by delivering bacteria-derived antigens coupled to specific IgG into mucosal immune cells, a genetically engineered C. rodentium strain was created that constitutively expresses an OVA fragment (residues 139-386 of chicken OVA) containing the peptides recognized by OT-II Tg T cells (residues 323-339) (C. rodentium-OVA) (see Methods). Immunoblot analysis confirmed the expression of OVA in the cell sonicates of C. rodentium-OVA but not control C. rodentium (Figure 4C). The bacterial sonicates from C. rodentium-OVA were also able to stimulate OVA-specific T cells from OT-II mice in in vitro culture with mitomycin $\mathrm{C}$-treated antigen-presenting cells from C57BL/6 mice (data not shown).
These results indicate that the OVA fragment produced by $C$. rodentium can be recognized by OVA-specific $\mathrm{CD} 4^{+} \mathrm{T}$ cells. To test whether FcRn-mediated delivery of IgG to host cells is required for the induction of immune responses to pathogens in vivo, IFABP$\mathrm{mFcRnTg} / \mathrm{m} \beta 2 \mathrm{mTg} / \mathrm{FcRn}{ }^{-/-}$and $\mathrm{FcRn}^{-/}$mice were infected with C. rodentium-OVA at 3 weeks of age. Anti-C. rodentium IgG or control IgG was injected at day 4 after infection, followed by adoptive transfer of CFSE-labeled OT-II T cells at day 5. Mononuclear cells from the MLNs were isolated at day 7 and examined by flow cytometry (Figure 4D). Injection of anti-C. rodentium IgG led to a significant increase in the number of $\mathrm{CD}^{+} \mathrm{OT}$-II cells, as demonstrated by the multiple cell divisions in CFSE-loaded OVA-specific $\mathrm{CD}^{+} \mathrm{T}$ cells in the MLNs (Figure 4E, arrows in right panel) of the IFABP-mFcRnTg/m $\beta 2 \mathrm{mTg} / \mathrm{FcRn}^{-/-}$mice infected with C. rodentium-OVA. In contrast, even in the presence of C. rodentium-OVA infection, no significant increase in the number of OVA-specific $\mathrm{CD}^{+} \mathrm{T}$ cells was detected in the MLNs of either IFABP-mFcRnTg/ $\mathrm{m} \beta 2 \mathrm{mTg} / \mathrm{FcRn}^{-/-}$mice that received control $\mathrm{IgG}$ or $\mathrm{FcRn}^{-1-}$ mice that received anti-C. rodentium IgG. Furthermore, injection of anti-C. rodentium IgG into IFABP-mFcRnTg/m $32 \mathrm{mTg} / \mathrm{FcRn}^{-1-}$ mice infected with $C$. rodentium-OVA led to increased production of IFN- $\gamma$ (Figure 4F) and IL-4 (Figure 4G) by MLN cells after in vitro OVA stimulation. These results indicate that epithelial FcRn can induce effective $\mathrm{CD}^{+} \mathrm{T}$ cell responses systemically to pathogen-derived antigens associated with the lumen and/or intestinal epithelium when they are retrieved as antigen/IgG complexes.

Intestinal bacterial antigens can be transported from the lumen as an immune complex into the lamina propria by $m F c R n$ in vivo and received by $C D 11 c^{+}$cells. Since normal enteric bacteria have recently been demonstrated to direct the maturation of the host immune system (14), we next established a model system to determine whether antibody in the serum could retrieve a physiologic bacterial antigen from the lumen into mucosal tissues when FcRn was expressed in the intestinal epithelium. To do so, rabbit anti-E. coli IgG (Figure 5A) or control IgG was injected i.v. into IFABP-mFcRn$\mathrm{Tg} / \mathrm{m} \beta 2 \mathrm{mTg} / \mathrm{FcRn}^{-/}$mice or $\mathrm{FcRn}^{-/-}$mice, and FITC-labeled E. coli (Figure 5B) was orally administered 12 hours after the i.v. injection. Two hours after oral administration, a FITC signal was detected in epithelial cells in the small intestine of the IFABP$\mathrm{mFcRnTg} / \mathrm{m} \beta 2 \mathrm{mTg} / \mathrm{FcRn}^{-/-}$mice in the presence of anti-E. coli IgG (Figure 5F), but not in the presence of control IgG (Figure 5E) or in the absence of FcRn (Figure 5, C and D). To examine whether the bacterial antigen/IgG complexes that were transported across epithelial cells by FcRn were taken up by DCs in gut-associated lymphoid tissue (GALT), as we have previously shown (2), cells were obtained from the MLNs 4 hours after the oral inoculation of FITC-E. coli and examined by flow cytometry. FITC-E. coli uptake by DCs in the MLNs was evident, as demonstrated by increased mean fluorescence intensity in the $\mathrm{CD} 11 \mathrm{c}^{+}$population within the MLNs obtained from IFABP-mFcRnTg $/ \mathrm{m} \beta 2 \mathrm{mTg} / \mathrm{FcRn}^{-/-}$mice in the presence of anti-E. coli IgG (Figure 5G). In contrast, the mean fluorescence intensity in CD $11 \mathrm{c}^{+}$cells from the MLNs of $\mathrm{FcRn}^{-/}$ mice that received anti-E. coli IgG was not significantly different from that observed in the $\mathrm{CD} 11 \mathrm{c}^{+}$cells from $\mathrm{FcRn}^{-1}$ mice that received control IgG (Figure 5G). No evidence of E. coli was evident in the MLNs, indicating that the fluorescence signal identified was not due to the presence of live bacteria (data not shown). These data indicate that FcRn in the epithelium delivers luminal bacterial antigens to GALT-associated CD $11 c^{+}$cells in the presence of circulating antibacterial IgG. 


\section{Discussion}

The recent recognition that FcRn can be expressed by mucosal epithelial cells in adult humans and that FcRn expression mediates an important physiological process that is characterized by bidirectional transport of $\operatorname{IgG}(11,12)$ has led to the notion that the in vivo function of FcRn is broader than the simple acquisition of passive immunity. This is further supported by the recent demonstration that human FcRn, when expressed as a transgene in mice under the control of its endogenous human promoter, can mediate the transport of a model antigen, OVA, from the lumen (2). This raises the possibility that a significant physiological function for $\mathrm{FcRn}$ is in mediating intestinal transport of bacterial antigens, given the intestine's constitutive exposure to a wide spectrum of enteric commensal and pathogenic bacteria. Therefore, this study was designed to establish and test an appropriate animal model in order to define the role of intestinal epithelial cell-associated FcRn in directing immune responses toward epithelial- and luminal-associated bacteria. To do so, we established what we believe to be a novel mouse model (IFABP-mFcRnTg/m $\beta 2 \mathrm{mTg} / \mathrm{FcRn}^{-/}$), in which $\mathrm{mFcRn}$ expression was genetically engineered to be specifically restricted to intestinal epithelial cells, and examined the response of these mice to luminal (E. coli) and epithelial cell-associated (C. rodentium) bacteria.

We herein demonstrate that intestinal luminal secretion of IgG was abrogated in $\mathrm{FcRn}^{-/}$mice. Importantly, the absence of FcRn was shown to enhance the susceptibility to infection of an intestinal pathogen, C. rodentium. However, selective restoration of FcRn expression in intestinal epithelial cells led to a reduction in susceptibility to this infection, but only in the presence of circulating IgG specific for this pathogen. These findings indicate that intestinal epithelial cell-associated FcRn is actively involved in the inhibition of an epithelial cell-associated pathogen, C. rodentium, by delivering IgG into the epithelial cell and/or intestinal lumen. Indeed IgG, but not secretory IgA or IgM, has been shown to play a critical role in the prevention against infection by the attaching and effacing pathogen C. rodentium (16-18). Mechanistically, it may be predicted that intestinal luminal IgG delivered from the lamina propria by $\mathrm{FcRn}$-mediated transport directly contributes to the suppression of $C$. rodentium infection.

There are 2 mechanisms by which FcRn in the epithelium may play a role in such a host defense function. The first possibility is that FcRn inhibits the adhesion and/or invasion of the bacterium by directing IgG into the location of the invading pathogen with or without the fixation of complement. The second possibility is that FcRn-mediated transcytosis of IgG activates C. rodentium-specific acquired immune responses. Such responses may be induced by DCs, which capture IgG/antigen complexes that are retrieved from the intestinal lumen through epithelial-associated FcRn. Indeed, we demonstrate here that intestinal epithelial cell-associated FcRn retrieved luminal bacterial antigens as a complex with IgG across epithelial barriers into the lamina propria in vivo. Importantly, the retrieved bacterial antigens were efficiently captured by DCs that were able to subsequently activate antigen-specific acquired immune responses by $\mathrm{CD} 4^{+} \mathrm{T}$ cells within the MLNs. The efficient capture of IgG/antigen complexes by DCs is consistent with recent studies showing uptake of immune complexes by DCs (26). Since $\mathrm{CD} 4^{+} \mathrm{T}$ cells have been shown to participate in prevention against $C$. rodentium infection $(16,18)$, FcRn may be an important and essential means to stimulate $\mathrm{CD} 4^{+} \mathrm{T}$ cell-mediated acquired immune responses to inhibit this, and potentially other, epithe- lial infections. Importantly, no increase in the number of CFSElabeled $\mathrm{CD}^{+} \mathrm{T}$ cells was observed in FcRn $\mathrm{Tg}$ mice in the absence of specific IgG, indicating an important role for FcRn-mediated antibody transport in regulating adaptive immune responses.

In addition to infection, these results may have important implications for the dysregulated host/microbial interactions that underlie the development of chronic intestinal inflammation associated with inflammatory bowel disease. Inflammatory bowel disease is notable for the presence of highly activated pathogenic $\mathrm{CD}^{+} \mathrm{T}$ cell populations (27). An increase in the production of IgG specific for luminal bacteria is also associated with the development of experimental colitis $(28,29)$. The bacterial antigens, which are recognized by such IgGs, are often identical to the antigens that drive the pathogenic $\mathrm{T}$ cell responses, as was recently shown for bacterial flagellins (30). Therefore, it is also possible that FcRnmediated retrieval of enteric bacterial antigens as IgG immune complexes may be - in some situations - involved in the pathogenesis of chronic colitis by activating harmful acquired immune responses. Consistent with this, FcRn has recently been implicated in the pathogenesis of rheumatoid arthritis (31) and bullous pemphigoid (32) by virtue of FcRn's ability to regulate IgG levels including pathogenic IgGs.

Enteric bacterial antigens are also involved in generating the normal structure and function of the GALT (14). The transport of intestinal antigens is tightly regulated by the epithelial layer, which anatomically provides an important barrier to separate the intestine from the luminal contents. M cells, a specialized epithelial cell type present in the follicle-associated epithelium, have been previously considered as the major "professional" antigen-sampling cell type that is capable of delivering luminal antigens into the lamina propria (33). In addition, intestinal DCs have been demonstrated to directly capture antigens or bacteria present in the intestinal lumen by opening the tight junctions between epithelial cells and sending dendrites into the lumen for antigen capture and retrieval $(34,35)$. We have recently demonstrated a third pathway, in which intestinal epithelial cell-associated FcRn is involved in sampling orally administrated antigens (such as food antigens) by retrieving the antigen as an IgG immune complex through absorptive epithelial cells (2). In the present study, by showing that commensal bacterial antigens (E. coli) could also be sampled from the intestinal lumen by an FcRn-mediated transport pathway and delivered into DCs within MLNs, our studies may have important implications for establishment of the normal GALT. It is presumed that these processes occur in situations wherein the host has acquired IgG either passively (e.g., neonatal rodent or human) or actively (e.g., after a primary immune response). In this context, the broad expression of FcRn in absorptive epithelia would allow for transport of luminal antigen over a wide surface area, allowing for broad flexibility in extending an opportunity for the host to respond to luminal antigen. In addition, recent studies have suggested that the manner in which antigen is taken up by a DC confers distinct functions on the DC (26). Interestingly, Fc $\gamma$ receptor IIB-mediated (Fc $\gamma$ RIIBmediated) capture of immune complexes are involved in the generation of DC-mediated immune tolerance through the activation of inhibitory motifs of these receptors (36). In addition, Igs have been proposed to suppress intestinal inflammation by facilitating phagocytosis of pathogenic antigens (37), and IgG in the lumen of the lung has been suggested to reduce allergen-induced asthma (38). Therefore, it is possible that the sampling of intestinal luminal antigens by an FcRn-mediated process contributes to unique, 
broadly expressed, and highly flexible functions of mucosal effector and/or regulatory pathways. These may be involved in the maintenance of mucosal tolerance characteristic of this compartment or the development of intestinal inflammation, as might occur if the transported antigen has adjuvant qualities. Such properties may have important consequences for establishing GALT structure during development and in response to pathogenic exposures.

In this study, we provide what we believe are novel insights into the role of FcRn when associated with the intestinal epithelium. FcRn in the epithelium is the primary means by which IgG reaches the lumen, as shown by the absence of luminal IgG in the context of FcRn deficiency. Moreover, FcRn may play a significant role in defending against epithelial-associated pathogens, as shown by increased sensitivity to C. rodentium in the absence of FcRn expression and by restoration of host resistance to C. rodentium in the context of $\mathrm{Tg} F \mathrm{CRn}$ reconstitution, specifically within the intestinal epithelium. We specifically associate this observation with FcRn's ability to provide this immune defense function in the presence of circulating IgG and to direct IgG into the lumen and antigen into DCs, whereupon adaptive immunity is enhanced. FcRn within the epithelium may thus be able to link microbial antigen encounters within the lumen and/or epithelium with systemic immune compartments. The ability of FcRn to provide these functions over a broad surface area may have important implications for understanding the development of GALT and its dysregulation in inflammation.

\section{Methods}

Animals. A Tg mouse strain in which both $\mathrm{mFcRn}$ and $\mathrm{m} \beta 2 \mathrm{~m}$ are constitutively and specifically expressed in the intestinal epithelial cells under the control of an IFABP (kindly provided by J. Gordon, Washington University, St. Louis, Missouri, USA) (20-22) was generated and further backcrossed to $\mathrm{FcRn}^{-/-}$mice (23) in order to eliminate $\mathrm{FcRn}$ expression in other cell types (IFABP-mFcRnTg $/ \mathrm{m} \beta 2 \mathrm{mTg} / \mathrm{FcRn}^{-/}$). These mice were backcrossed 6 generations onto either BALB/c or C57BL/ $6\left(\mathrm{CD} 45.2^{+}\right)$. For OVA studies, OT-II mice were used (39), which express a restricted $\mathrm{Tg} \mathrm{T}$ cell receptor that recognizes a peptide fragment of OVA (residues 323-339) in the context of $\mathrm{I}-\mathrm{A}^{\mathrm{b}}\left(\mathrm{CD} 45.1^{+} \mathrm{C} 57 \mathrm{BL} / 6\right)$. These studies were approved by the Standing Committee on Animals at Harvard Medical School.

$R T-P C R$. Epithelial cells were nonenzymatically isolated as described previously (40), and total RNA was extracted using TRIzOL reagent (Invitrogen). RT-PCR reaction was carried out using specific primer sets for $\mathrm{mFcRn}, \mathrm{m} \beta 2 \mathrm{~m}$, and $\mathrm{m} \beta$-actin as described previously (41).

Quantitative PCR. Tissues were collected into RNAlater (Ambion), and total RNA was extracted using TRIzol reagent (Invitrogen). For the expression analysis of the $\mathrm{mFcRn}$ transgene, specific primer sets for the mFcRn transgene (Primer 1, 5'-GCCCTCAGCCTCTTGTTGG-3'; Primer 2, 5'-CCCGTAGATGGGTTTGACACA-3') were used for amplification with detection of a 102-bp cDNA fragment. Quantitative PCR was carried out with $1 \mu \mathrm{l}$ cDNA in the presence of iQ SYBR Green Supermix (BioRad) and an iQ5 Real-Time PCR Detection System (Bio-Rad) for real-time detection. $\mathrm{mFcRn}$ transgene expression levels were determined via the comparative cycle threshold $\left(2^{-\Delta \Delta C t}\right)$ methods (Applied Biosystems User Bulletin 2) and normalized to $\mathrm{m} \beta$-actin.

Immunohistochemistry. For the detection of $\mathrm{mFcRn}$, tissues were snap-frozen and subjected to immunohistochemical staining (42) using rabbit antiFcRn antibodies (kindly provided by N.E. Simister, Brandeis University, Waltham, Massachusetts, USA). For the detection of C. rodentium, sections were stained for intimin using the polyclonal rabbit anti-C. rodentium intimin sera (kindly provided G. Frankel, Imperial College, London, United
Kingdom) followed by Alexa ${ }^{564}$-conjugated anti-rabbit IgG (Molecular Probes) and nuclei and examined under confocal microscopy (MRC1024 laser scanning confocal system; Bio-Rad).

Detection of serum and secretory mouse and rabbit Ig. Secretory mouse and rabbit Igs present in the intestinal lumen were assessed by ELISA as previously described (2). The levels of Igs (IgG1, IgG2a, IgG2b, IgG3, IgA, IgM, and $\operatorname{IgE}$ ) secreted into the lumen were also examined by an alternative method, a cytometric bead array performed according to the manufacturer's instruction (BD Biosciences - Pharmingen). The collected feces were resuspended in PBS and incubated with the fluorescent beads at concentrations that were normalized for the quantities of protein. After incubation with anti-mouse $\kappa$ detector antibodies, the beads were analyzed by flow cytometry. To examine IgG production by the MLNs, mononuclear cells were collected from the MLNs of $\mathrm{FcRn}^{-/}$, IFABP-mFcRnTg/m $\beta 2 \mathrm{mTg}$, and WT control mice $(\mathrm{C} 57 \mathrm{BL} / 6)$. Cells $\left(1 \times 10^{7} / \mathrm{ml}\right)$ in PBS $(\mathrm{pH} 7.4)$ were cultured without any in vitro stimulation for 2 hours on $37^{\circ} \mathrm{C}$, after which the Ig levels were evaluated by flow cytometric analysis as described above.

Preparation of cell suspensions. Antigen-presenting cells were isolated using a digestion buffer, as described previously (2), with a modification. Cells were carefully collected from the interface, washed with PBS, and used.

Protocol for induction of colitis by C. rodentium infection. C. rodentium strain DBS100 (catalog no. 51459; ATCC) was used. 3-week-old mice were orally infected as described previously (16). OVA-expressing C. rodentium was created by electroporating plasmid DH136 into C. rodentium strain DBS100. DH136 contains a cassette of the pTR(lac) promoter driving expression of residues 139-386 of chicken OVA, cloned into the EcoRV site of the low-copy plasmid pACYC184 (chloramphenicol selection). pTR(lac) drives constitutive expression of OVA. After electroporation with a Bio-Rad Gene Pulser II, chloramphenicol-resistant transformants were verified to retain normal production of LPS and to constitutively express the 139-386 fragment of OVA. To ensure maintenance of the plasmid during in vivo infection, $500 \mu \mathrm{g} / \mathrm{ml}$ chloramphenicol was added to the drinking water. All methods and procedures with infected animals were performed in BL-2 safety cabinets. Colonic tissues with $\mathrm{H} \& \mathrm{E}$ stain were evaluated by a pathologist (J.N. Glickman) in a blinded fashion, and results were represented as a total score (43).

Adoptive transfer, CFSE labeling of OVA-specific OT-II CD4 ${ }^{+} \mathrm{T}$ cells, and antigenic challenge of C. rodentium-OVA. IFABP- $\mathrm{mFcRnTg} / \mathrm{m} \beta 2 \mathrm{mTg} / \mathrm{FcRn}^{-1-}$ or $\mathrm{FcRn}^{-/-} \mathrm{C} 57 \mathrm{BL} / 6$ mice ( 3 weeks old) were orally infected with $1 \times 10^{9} \mathrm{CFU}$ of C. rodentium-OVA or WT C. rodentium. The mice received $2 \mathrm{mg}$ of antiC. rodentium IgG or control IgG i.v. at day 4 after the bacterial inoculation and subsequently received CFSE-labeled CD $45.1^{+} \mathrm{CD} 4{ }^{+} \mathrm{OT}-\mathrm{II} \mathrm{T}$ cells for the detection of cell division or nonlabeled $\mathrm{CD} 45.1^{+} \mathrm{CD} 4^{+} \mathrm{OT}$-II $\mathrm{T}$ cells for examination of antigen-specific cytokine production by adoptive transfer at day 5. Cytokine measurements were made with $\mathrm{CD} 4^{+} \mathrm{T}$ cells prepared from MLNs and stimulated with C57BL/6 splenocytes pulsed with OVA as antigen-presenting cells. On day 7, MLN cells were subjected to flow cytometric analysis for the evaluation of CFSE intensity (indicating cell division) of the $\mathrm{CD} 4^{+} \mathrm{T}$ cells gated on $\mathrm{CD} 45.1^{+}$cells.

Preparation of FITC-E. coli and in vivo transcytosis of antigen/IgG complexes. E. coli (DH5 $\alpha$; Invitrogen) was labeled with $1 \mathrm{mg} / \mathrm{ml}$ of FITC solution in $\mathrm{PBS}$ at $\mathrm{pH} 7.4$ for 15 minutes. To analyze the transcytosis of bacterial antigen/IgG complexes, $2 \mathrm{mg}$ rabbit anti-E. coli IgG (Dako) or control IgG was injected i.v. into mice. FITC-conjugated E. coli $\left(1 \times 10^{9}\right.$ cells $)$ was administered intragastrically 12 hours after the i.v. injection of IgG, and tissue from the mid-small intestine was collected 2 hours after the oral inoculation. Tissue sections were subjected to staining for detection of actin (phalloidin; red) and nuclei (blue) and examined by confocal microscopy as previously described. MLN cells were isolated 5 hours after oral inoculation, stained with PE-conjugated anti-CD11c and 7-amino-actinomycin D (7-AAD) to exclude dead cells, and examined by flow cytometry. 
Statistics. Statistical significance was determined by a 2-tailed Student's $t$ test. $P$ values less than 0.05 were considered significant.

\section{Acknowledgments}

This work was supported in part by Research Fellowships from Crohn's and Colitis Foundation of America (M. Yoshida, T. Nagaishi, and A. Kaser) and by NIH grant DK53056 (R.S. Blumberg and W.I. Lencer), Harvard Digestive Diseases Center grant P30 (R.S. Blumberg and W.I. Lencer), and NIH grants DK51362 and DK44319 (R.S. Blumberg). A. Mizoguchi was supported by NIH grant DK64351, and E. Mizoguchi was supported by NIH grant DK64289.

1. Robert-Guroff, M. 2000. IgG surfaces as an important component in mucosal protection. Nat. Med. 6:129-130

2. Yoshida, M., et al. 2004. Human neonatal Fc receptor mediates transport of IgG into luminal secretions for delivery of antigens to mucosal dendritic cells. Immunity. 20:769-783.

3. Woof, J.M., and Mestecky, J. 2005. Mucosal immunoglobulins. Immunol. Rev. 206:64-82.

4. Hanson, L.A., and Brandzaeg, P. 1980. The mucosal defense system. In Immunologic disorders in infants and children. Stiehm, E.R., editor. W.B. Saunders. Philadelphia, Pennsylvania, USA. 137-164.

5. Kozlowski, P.A., Cu-Uvin, S., Neutra, M.R., and Flanigan, T.P. 1997. Comparison of the oral, rectal, and vaginal immunization routes for induction of antibodies in rectal and genital tract secretions of women. Infect. Immun. 65:1387-1394.

6. Brandtzaeg, P., and Johansen, F.E. 2005. Mucosal B cells: phenotypic characteristics, transcriptional regulation, and homing properties. Immunol. Rev. 206:32-63.

7. Simister, N.E., and Mostov, K.E. 1989. An Fc receptor structurally related to MHC class I antigens. Nature. 337:184-187.

8. Dickinson, B.L., et al. 1999. Bidirectional FcRndependent IgG transport in a polarized human intestinal epithelial cell line. J. Clin. Invest. 104:903-911.

9. Israel, E.J., et al. 1997. Expression of the neonatal Fc receptor, FcRn, on human intestinal epithelial cells. Immunology. 92:69-74.

10. Bitonti,A.J., et al. 2004. Pulmonary delivery of an erythropoietin Fc fusion protein in non-human primates through an immunoglobulin transport pathway. Proc. Natl. Acad. Sci. U. S. A. 101:9763-9768.

11. Claypool, S.M., et al. 2004. Bidirectional transepithelial IgG transport by a strongly polarized basolateral membrane Fcgamma-receptor. Mol. Biol. Cell. 15:1746-1759.

12. Claypool, S.M., Dickinson, B.L., Yoshida, M., Lencer, W.I., and Blumberg, R.S. 2002. Functional reconstitution of human FcRn in Madin-Darby canine kidney cells requires coexpressed human beta 2-microglobulin. J. Biol. Chem. 277:28038-28050.

13. Spiekermann, G.M., et al. 2002. Receptor-mediated immunoglobulin $\mathrm{G}$ transport across mucosal barriers in adult life: functional expression of FcRn in the mammalian lung. J. Exp. Med. 196:303-310.

14. Mazmanian, S.K., Liu, C.H., Tzianabos, A.O., and Kasper, D.L. 2005. An immunomodulatory molecule of symbiotic bacteria directs maturation of the host immune system. Cell. 122:107-118.

15. Kraus, T.A., et al. 2005. Induction of mucosal tolerance in Peyer's patch-deficient, ligated small bowel loops. J. Clin. Invest. 115:2234-2243. doi:10.1172/JCI19102.

16. Bry, L., and Brenner, M.B. 2004. Critical role of T

Received for publication January 3, 2006, and accepted in revised form May 16, 2006.

Address correspondence to: Richard S. Blumberg, Gastroenterology Division, Department of Medicine, Brigham and Women's Hospital and Harvard Medical School, 75 Francis Street, Boston, Massachusetts 02115, USA. Phone: (617) 732-6917; Fax: (617) 264-5185; E-mail: rblumberg@partners.org.

Masaru Yoshida's present address is: Frontier Medical Science in Gastroenterology, International Center for Medical Research and Treatment, Kobe University School of Medicine, Kobe, Japan.

cell-dependent serum antibody, but not the gutassociated lymphoid tissue, for surviving acute mucosal infection with Citrobacter rodentium, an attaching and effacing pathogen. J. Immunol. 172:433-441.

17. Maaser, C., et al. 2004. Clearance of Citrobacter rodentium requires B cells but not secretory immunoglobulin A (IgA) or IgM antibodies. Infect. Immun. 72:3315-3324.

18. Simmons, C.P., et al. 2003. Central role for B lymphocytes and CD4+ T cells in immunity to infection by the attaching and effacing pathogen Citrobacter rodentium. Infect. Immun. 71:5077-5086.

19. Ghetie, V., et al. 1996. Abnormally short serum half-lives of IgG in beta 2-microglobulin-deficient mice. Eur. J. Immunol. 26:690-696.

20. Sweetser, D.A., et al. 1987. The human and rodent intestinal fatty acid binding protein genes. A comparative analysis of their structure, expression, and linkage relationships. J. Biol. Chem. 262:16060-16071.

21. Cohn, S.M., Simon, T.C., Roth, K.A., Birkenmeier, E.H., and Gordon, J.I. 1992. Use of transgenic mice to map cis-acting elements in the intestinal fatty acid binding protein gene (Fabpi) that control its cell lineage-specific and regional patterns of expression along the duodenal-colonic and crypt-villus axes of the gut epithelium. J. Cell Biol. 119:27-44.

22. Rottman, J.N., and Gordon, J.I. 1993. Comparison of the patterns of expression of rat intestinal fatty acid binding protein/human growth hormone fusion genes in cultured intestinal epithelial cell lines and in the gut epithelium of transgenic mice. J. Biol. Chem. 268:11994-12002.

23. Roopenian, D.C., et al. 2003. The MHC class I-like IgG receptor controls perinatal IgG transport, IgG homeostasis, and fate of IgG-Fc-coupled drugs. J. Immunol. 170:3528-3533.

24. Ober, R.J., Radu, C.G., Ghetie, V., and Ward, E.S. 2001. Differences in promiscuity for antibody-FcRn interactions across species: implications for therapeutic antibodies. Int. Immunol. 13:1551-1559.

25. Vallance, B.A., Deng, W., Jacobson, K., and Finlay, B.B. 2003. Host susceptibility to the attaching and effacing bacterial pathogen Citrobacter rodentium. Infect. Immun. 71:3443-3453.

26. Mellman, I., and Steinman, R.M. 2001. Dendritic cells: specialized and regulated antigen processing machines. Cell. 106:255-258.

27. Strober, W., Fuss, I.J., and Blumberg, R.S. 2002. The immunology of mucosal models of inflammation. Annu. Rev. Immunol. 20:495-549.

28. Brandwein, S.L., et al. 1997. Spontaneously colitic $\mathrm{C} 3 \mathrm{H} / \mathrm{HeJBir}$ mice demonstrate selective antibody reactivity to antigens of the enteric bacterial flora. J. Immunol. 159:44-52.

29. Mizoguchi, E., Mizoguchi, A., Chiba, C., Niles, J.L., and Bhan, A.K. 1997. Antineutrophil cyto- plasmic antibodies in T-cell receptor alpha-deficient mice with chronic colitis. Gastroenterology. 113:1828-1835.

30. Lodes, M.J., et al. 2004. Bacterial flagellin is a dominant antigen in Crohn disease. J. Clin. Invest. 113:1296-1306. doi:10.1172/JCI200420295.

31. Akilesh, S., et al. 2004. The MHC class I-like Fc receptor promotes humorally mediated autoimmune disease. J. Clin. Invest. 113:1328-1333. doi:10.1172/JCI200418838.

32. Li, N., et al. 2005. Complete FcRn dependence for intravenous Ig therapy in autoimmune skin blistering diseases. J. Clin. Invest. 115:3440-3450. doi:10.1172/JCI24394.

33. Iwasaki, A., and Kelsall, B.L. 1999. Mucosal immunity and inflammation. I. Mucosal dendritic cells: their specialized role in initiating $\mathrm{T}$ cell responses. Am. J. Physiol. 276:G1074-G1078.

34. Rescigno, M., et al. 2001. Dendritic cells express tight junction proteins and penetrate gut epithelial monolayers to sample bacteria. Nat. Immunol. 2:361-367.

35. Niess, J.H., et al. 2005. CX3CR1-mediated dendritic cell access to the intestinal lumen and bacterial clearance. Science. 307:254-258.

36. Kalergis, A.M., and Ravetch, J.V. 2002. Inducing tumor immunity through the selective engagement of activating Fcgamma receptors on dendritic cells. J. Exp. Med. 195:1653-1659.

37. Mizoguchi, A., Mizoguchi, E., Smith, R.N., Preffer, F.I., and Bhan, A.K. 1997. Suppressive role of B cells in chronic colitis of $\mathrm{T}$ cell receptor alpha mutant mice. J. Exp. Med. 186:1749-1756.

38. Sehra, S., et al. 2003. Airway IgG counteracts specific and bystander allergen-triggered pulmonary inflammation by a mechanism dependent on Fc gamma $R$ and IFN-gamma. J. Immunol. 171:2080-2089.

39. Barnden, M.J., Allison, J., Heath, W.R., and Carbone, F.R. 1998. Defective TCR expression in transgenic mice constructed using cDNA-based alpha- and beta-chain genes under the control of heterologous regulatory elements. Immunol. Cell Biol. 76:34-40.

40. Blumberg, R.S., et al. 1991. Expression of a nonpolymorphic MHC class I-like molecule, CD1D, by human intestinal epithelial cells. J. Immunol. 147:2518-2524.

41. Zhu, X., et al. 2001. MHC class I-related neonatal Fc receptor for IgG is functionally expressed in monocytes, intestinal macrophages, and dendritic cells. J. Immunol. 166:3266-3276.

42. Mizoguchi, E., Mizoguchi, A., and Bhan, A.K. 1997. Role of cytokines in the early stages of chronic colitis in TCR alpha-mutant mice. Lab. Invest. 76:385-397.

43. Neurath, M.F., et al. 2002. The transcription factor $\mathrm{T}$-bet regulates mucosal $\mathrm{T}$ cell activation in experimental colitis and Crohn's disease. J. Exp. Med. 195:1129-1143. 